\title{
ФАКТОРЫ РИСКА В ОРГАНИЗАЦИЯХ НЕФТЕПЕРЕРАБАТЫВАЮЩЕЙ ОТРАСЛИ
}

\author{
Мищенко Ю.А. \\ магистрант \\ Калитко С.A. \\ к.э.н., доиент
}

ФГБОУ ВО Кубанский ГАУ

\begin{abstract}
Аннотация. Неопределенность понижает эффективность проводимых мероприятий, связанных с планированием деятельности, формированием инвестиционной стратегии и устойчивости к изменениям спроса и предложения. Идентификация и изучение факторов риска в отрасли позволит минимизировать последствия неблагоприятного воздействия и управлять соответствующими рисками.

Annotation. Uncertainty lowers the efficiency of activities related to planning activities, the formation of an investment strategy and resilience to changes in supply and demand. Identifying and studying risk factors in the industry will help minimize the impact of adverse impacts and manage the associated risks.
\end{abstract}

Ключевые слова: риск, факторы риска, нефтеперерабатывающая отрасль, управление рисками

Key words: risk, risk factors, oil refining industry, risk management

В процессе своей работы организации, которые специализируются в нефтегазовой отрасли, могут быть подвержены большому количеству рисков, которые, в свою очередь, могут отрицательно сказываться на производственных и финансовых результатах. Каждая организация стремится к снижению уровня рисков, которые находятся под их контролем, стараясь учесть все возможные негативные последствия рисков [1].

На протяжении десятков лет специалисты возвращались к решению важного вопроса - какова возможность эффективного управления рисками в условиях объективной неопределенности. Обращая внимание на позитивное отношение к тому, что происходит перестроение мировой экономики в положительную сторону, государство попрежнему остается хрупким.

Компания «Ernst\&Young» проводила исследования в области бизнес-рисков и ежегодно определяла из них основные, влияющие на деятельность нефтегазовых организаций в мире. По мнению аналитиков данной компании, самый главный риск для нефтегазовых организаций сегодня - это ограниченная доступность запасов. Данный вывод был сделан в отчете «Ernst \& Young» «Преобразование рисков и возможностей в результаты» [2].

Нами в процессе исследования был использован алгоритм управления рисками в инвестиционных проектах нефтеперерабатывающих производств для ПАО «Газпром» (рисунок 1). Он представляет возможным производить комплексные и всеобъемлющие обоснования инвестиций в процесс переработки нефти и газа с учетом интересов как государства, так и бизнеса с обязательным учетом всевозможных рисков.

Данный процесс начинается с анализа событий, которые полностью отображают изменения внешней окружающей среды и внутренних особенностей деятельности организаций, которые происходят со $100 \%$ гарантией.

Затем выявляются и анализируются с использованием различных методов возможные неблагоприятные последствия, которые с определенной вероятностью могут отразиться на финансовых показателях организации. Если полученная оценка уровня риска не превышает его допустимое или пороговое значение, то функция контроля прекращается, и протокол риска передается в архив. Однако, если уровень риска превышает допустимое значение, то необходима разработка и реализация управленческого решения, направленного на минимизацию риска. 


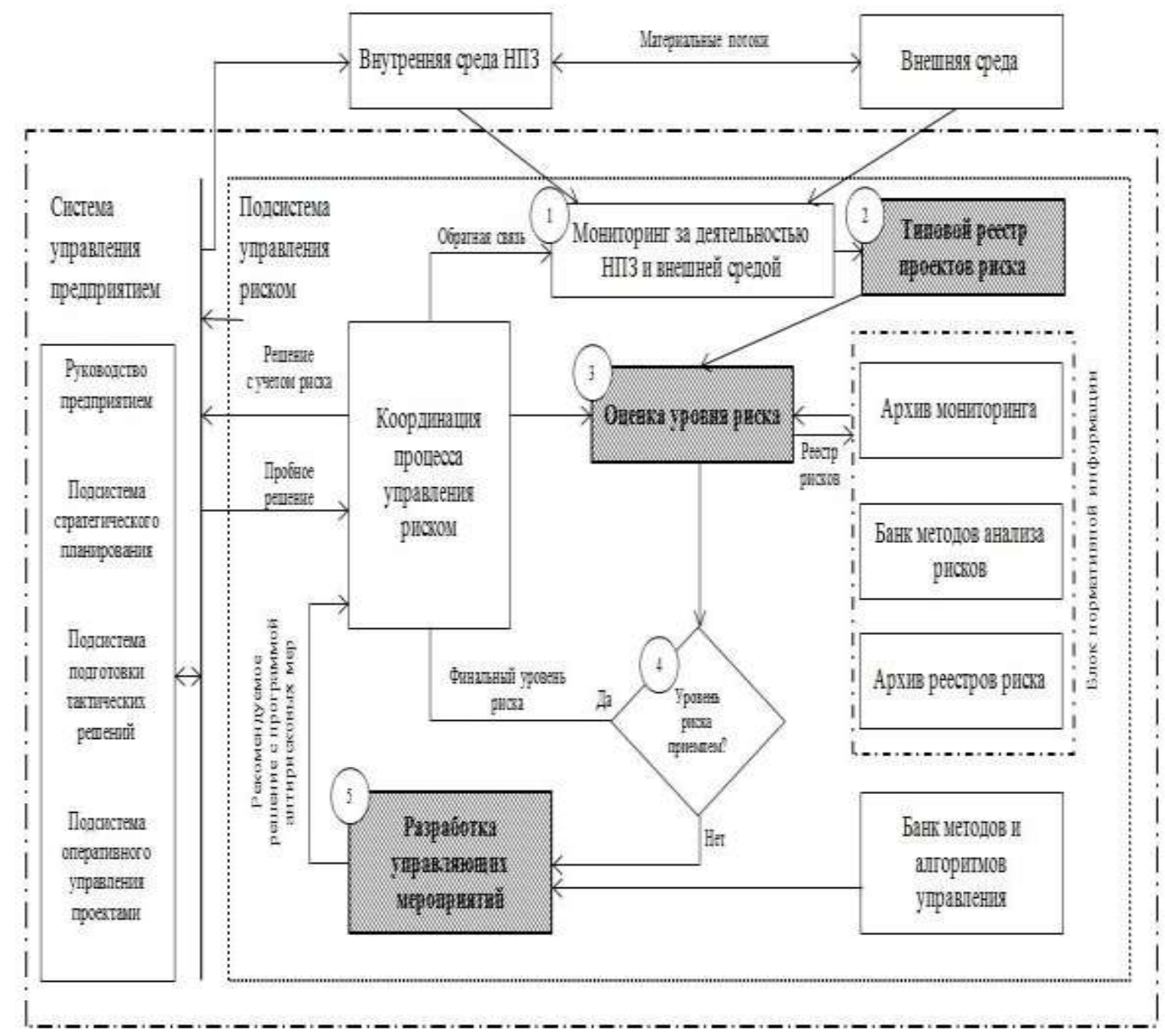

Рисунок 1 - Алгоритм управления рисками в инвестиционных проектах нефтеперерабатьвающих производств [4]

ПАО «Газпром» - глобальная энергетическая компания. Основные направления деятельности геологоразведка, добыча, транспортировка, хранение, переработка и реализация нефтепродуктов. Стратегической целью «Газпрома» является укрепление статуса лидера среди глобальных энергетических компаний посредством диверсификации рынков сбыта, обеспечения энергетической безопасности и устойчивого развития, роста эффективности деятельности, использования научно-технического потенциала.

Рассмотрим самые основные риски на примере ПАО «Газпром», которые были выявлены экспертами нефтегазовой отрасли, их актуальность может возрасти в ближайшем времени.

Политика, связанная с энергетическими ресурсами во многих нефтедобывающих странах, постоянно меняется. Данная неопределенность понижает эффективность проводимых мероприятий, связанных с планированием деятельности, формированием инвестиционной стратегии и устойчивости к изменениям спроса и предложения.

Рассмотрим ситуацию, с которой «Газпром» столкнулся с колоссальными проблемами в виде того, что объемов добычи газа на одном из крупнейших месторождений России - Чаядинском - может не хватить, чтобы заполнить газопровод «Сила Сибири», что в свою очередь грозит срывом 30-летнего контракта на поставку газа между Россией и Китаем, а «Газпром» рискует потерять более 1,5 триллиона рублей. К этому привели ошибки персонала, последствия импортозамещения.

Обеспечение эффективного контроля затрат позволяет оптимизировать денежные потоки. На фоне текущей ситуации в мировой экономике ряд организаций руководствуется определенной стратегией, стремясь сохранить уровень прибыльности. Кроме того, реализация таких мер может привести к сбоям в работе, негативно повлиять на выручку компании, взаимодействовать с покупателями и выполнять обязательства по договорам поставки. 
Кроме этого, серьезное влияние на нефть и газ оказала ситуация с карантинными мерами, из-за которых по всему миру остановилась часть организаций. Из-за чего снизился спрос на углеводороды. «Газпром» значительно теряет от текущей ситуации на рынке. В январе-апреле 2020 г. доходы от экспорта «Газпрома» упали на 52,3 \% по сравнению с прошлым уровнем. Текущая цена по «Газпрому» - это большой аванс организации, ставка на 2021-2022 гг. Только после восстановления газового рынка с новой дивидендной политикой, организация сможет генерировать большой доход для своих акционеров.

Большое количество слабо освоенных месторождений нефти и газа располагаются в малоизученных и труднодоступных территориях (биту-минозные пески в Канаде, месторождения в Арктике и глубоководные месторождения). Данный фактор значительно увеличивает затраты на добычу и разведку данных месторождений, а также приводит к увеличению рисков, которые связаны с объективной необходимостью вспомогательных капитальных вложений. Также добычу полезных ископаемых опережает геологоразведка местности, так как это трудоемкий процесс, то он может затягиваться на несколько лет. Чаядинское месторождение - тот случай, когда географическое расположение способствует и существует необходимость развивать инфраструктуру нетронутой Сибири. В итоге 21 февраля 2020 года был разыгран тендер на сумму 9,6 млн. руб. Одним из самых важных элементов разведывательных работ считается анализ породы пластов, которые предстоит бурить.

В ближайший период ожидается усиление конкуренции между международными и национальными нефтяными организациями за доступ к новым месторождениям. В отличие от международных нефтяных организаций, национальные организации имеют ряд существенных преимуществ: поддержку со стороны государства и государственных инвестиционных фондов, а также географическую близость к рынкам азиатских стран с формирующейся экономикой.

К примеру, темпы роста добычи сланцевого газа в США в ближайшие годы могут значительно снизиться, а развитие этой отрасли в других странах в перспективе до 2030 года не окажет значимого влияния на мировой рынок газа и деятельность «Газпрома». В «Газпроме» обсуждают, что в этом году из-за низкой конкурентоспособности поставок из США покупатели отказались от большого числа партий СПГ из этой страны.

Нефтегазовые организации являются объектом пристального внимания не только со стороны государства. Сегодня организации отрасли сталкиваются с растущим давлением со стороны акционеров с целью информации о вероятности возникновения экологических рисков. В связи с экологической катастрофой, вызванной разливом нефти в Мексиканском заливе, некоторые инвесторы ожидают полного раскрытия информации об угрозах, связанных с морским бурением и возможными экологическими последствиями морских буровых работ, а также о мерах, реализуемых в нефтегазовых организациях по предотвращению подобных аварий, минимизации их последствий и управлению соответствующими рисками.

По мере проведения поисков и разведки дополнительная информация о параметрах прогнозируемого месторождения и ранее существовавшей неопределенности снижается. Принципиальная схема соотношения управляемых рисков и масштабов инвестиций на разных этапах изучения и развития ресурсов углеводородов показаны на рисунке 2 .

К примеру, когда была разработана стадия разведки глубоководного месторождения, масштаб финансирования достигал 1 млрд. руб., а уже на самой стадии разведки - 4 млрд. руб. Самые крупные объемы рисковых вложений в достаточно крупное по нефтезапасам шельфовых месторождений может достигать 25-65 млрд. руб., хотя если рассматривать саму геологическую ценность, то она минимальна на данном этапе производимых работ.

Проблема нехватки высококвалифицированных кадров остается актуальной вне зависимости от экономической ситуации. По мере восстановления экономики отрасль будет испытывать все большую потребность в высококвалифицированных специалистах, дефицит которых может привести к срыву сроков или отмене проектов, снижению производительности и увеличению операционных расходов. 


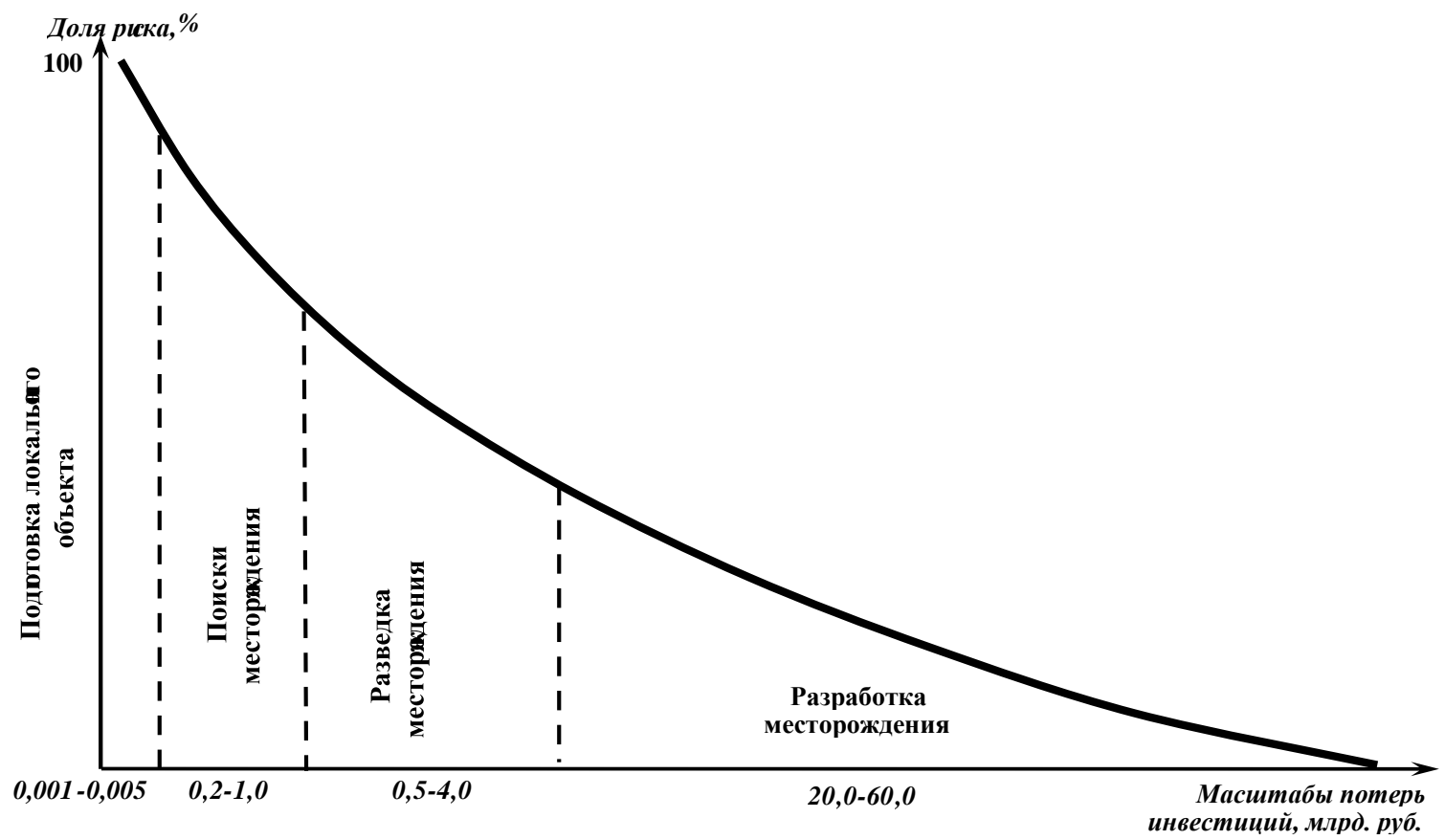

Рисунок 2 - Принципиальная схема соотношения риска и масштабов потерь инвестиций на разных стадиях прочесса изучения и освоения углеводородных ресурсов [4]

Таким образом, факторы риска, влияющие на деятельность организаций нефтеперерабатывающей отрасли, требует постоянного изучения для своевременной идентификации рисков в целях эффективного управления рисками в условиях неопределенности для нефтегазовых организаций, которая для них остается актуальной [7, 8, 9].

\section{Список использованной литературы}

1. Зубарева В., Саркисов А. Проектные риски в нефтегазовой промышленности. - 2020.

2. Отчет «Эрнст энд Янг» «Основные риски для компаний нефтегазовой отрасли», 2019.

3. Отчет «Эрнст энд Янг» «Исследования и аналитика». - 2019.

4. Кот А.Д., Шмидт А.П. [Электронный ресурс]: Управление рисками при эксплуатации нефтегазовых объектов. - / А. Д. Кот, А.П. Шмидт. - URL: http://elib.tyuiu.ru/wp-content : Тюмень, 2019.

5. Официальный сайт ПАО «Газпром» [Электронный ресурc] - URL: http://www.gazprom.ru/ (Дата обращения $01.12 .2020)$

6. Официальный сайт ПАО «Газпром нефть» [Электронный pecypc] - URL: https://www.gazprom-neft.ru/ (Дата обращения 01.12.2020)

7. Гайдук, В. И., Калитко, С. А., Москалевич, А. А. Диверсификация как прием снижения степени риска в предпринимательской деятельности // Экономика сельскохозяйственных и перерабатывающих предприятий. 2012. - №2. - С. 24-26.

8. Гайдук, В. И., Даниленко, Д. А., Калитко, С. А., Григорян, Г. Ю. Состояние и перспективы развития ПАО «НК «РОСНЕФТЬ» // Экономика и предпринимательство. - 2018. - №8 (97). - С. 912-916.

9. Калитко, С. А., Секерин, В. Д., Горохова, А. Е. Управление рисками. - Краснодар, 2019. 